\title{
Evidence-based practice guidelines for plasma transfusion
}

\author{
John D. Roback, Stephen Caldwell, Jeff Carson, Robertson Davenport, Mary Jo Drew, Anne Eder, \\ Mark Fung, Marilyn Hamilton, John R. Hess, Naomi Luban, Jeremy G. Perkins, Bruce S. Sachais, \\ Aryeh Shander, Toby Silverman, Ed Snyder, Christopher Tormey, John Waters, and Ben Djulbegovic
}

BACKGROUND: There is little systematically derived evidence-based guidance to inform plasma transfusion decisions. To address this issue, the AABB commissioned the development of clinical practice guidelines to help direct appropriate transfusion of plasma.

STUDY DESIGN AND METHODS: A systematic review (SR) and meta-analysis of randomized and observational studies was performed to quantify known benefits and harms of plasma transfusion in common clinical scenarios (see accompanying article). A multidisciplinary guidelines panel then used the SR and the GRADE methodology to develop evidence-based plasma transfusion guidelines as well as identify areas for future investigation.

RESULTS: Based on evidence ranging primarily from moderate to very low in quality, the panel developed the following guidelines: 1) The panel suggested that plasma be transfused to patients requiring massive transfusion. However, 2) the panel could not recommend for or against transfusion of plasma at a plasma : red blood cell ratio of $1: 3$ or more during massive transfusion, 3) nor could the panel recommend for or against transfusion of plasma to patients undergoing surgery in the absence of massive transfusion. 4) The panel suggested that plasma be transfused in patients with warfarin therapy-related intracranial hemorrhage, 5) but could not recommend for or against transfusion of plasma to reverse warfarin anticoagulation in patients without intracranial hemorrhage. 6) The panel suggested against plasma transfusion for other selected groups of patients.

CONCLUSION: We have systematically developed evidence-based guidance to inform plasma transfusion decisions in common clinical scenarios. Data from additional randomized studies will be required to establish more comprehensive and definitive guidelines for plasma transfusion.
ABBREVIATIONS: ACCP = American College of Chest Physicians; CTMC = Clinical Transfusion Medicine Committee; $\mathrm{EBM}=$ evidence-based medicine; $\mathrm{GRADE}=$ Grading of Recommendations, Assessment, Development, and Evaluation; FP24 = plasma frozen within 24 hours after phlebotomy; $\mathrm{PG}(\mathrm{s})=$ practice guideline $(\mathrm{s}) ; \mathrm{SR}=$ systematic review.

From the Center for Transfusion and Cellular Therapies, Department of Pathology and Laboratory Medicine, Emory University School of Medicine, Atlanta, Georgia; GI/Hepatology, University of Virginia, Charlottesville, Virginia; the UMDNJ/Robert Wood Johnson University Hospital, New Brunswick, New Jersey; the Blood Bank and Transfusion Service, Department of Pathology, University of Michigan Medical School, Ann Arbor, Michigan; the American Red Cross, Pacific Northwest Blood Services Region, Portland, Oregon; the American Red Cross, Biomedical Services, National Headquarters, Washington, DC; the Department of Pathology, Fletcher Allen Health Care and University of Vermont, Burlington, Vermont; Children's Mercy Hospital, Kansas City, Missouri; the Department of Pathology, University of Maryland Medical Center, Baltimore, Maryland; the Children's Hospital National Medical Center, Washington, DC; the Department of Blood Research, Walter Reed Army Institute of Research, Silver Spring, Maryland; the Division of Transfusion Medicine, Department of Pathology and Laboratory Medicine, Penn Medicine, University of Pennsylvania, Philadelphia, Pennsylvania; the Department of Anesthesiology, Mt. Sinai School of Medicine, Englewood Hospital and Medical Center, Englewood, New Jersey; the US Food and Drug Administration, Rockville, Maryland; Laboratory Medicine, Yale-New Haven Hospital, New Haven, Connecticut; the University of Pittsburgh Medical Center, Pittsburgh, Pennsylvania; and the Center for Evidence-based Medicine and Health Outcome Research, Clinical Translational Science Institute, University of South Florida and H. Lee Moffitt Cancer Center \& Research Institute, Tampa, Florida.

Address reprint requests to: John D. Roback, Center for Transfusion and Cellular Therapies, Department of Pathology and Laboratory Medicine, Emory University School of Medicine, Atlanta, GA 30322; e-mail: jroback@emory.edu.

Received for publication November 12, 2009; revision

received January 22, 2010, and accepted January 23, 2010.

doi: 10.1111/j.1537-2995.2010.02632.x

TRANSFUSION 2010;50:1227-1239. 
$\mathrm{P}$ lasma transfusion is commonly prescribed for a variety of indications, including to replace volume and coagulation factors during massive transfusion, to prevent further or future bleeding in patients undergoing invasive procedures, to reverse warfarin therapy in patients with or without bleeding, and to address isolated coagulation factor abnormalities. Plasma for transfusion is usually termed fresh-frozen plasma (FFP, plasma frozen within 8 hours after phlebotomy) in everyday use as well as in the literature, although many plasma units transfused in the United States are actually frozen within 24 hours after phlebotomy (FP24). The primary difference between these products is that cryoprecipitate can be manufactured from FFP but not FP24, although FFP and FP24 can be transfused interchangeably. Thawed plasma (either FFP of FP24) stored for up to 5 days before administration is also commonly used for transfusion. (For simplicity, the term "plasma" is used throughout the text to refer to FFP, FP24, or thawed plasma.) The scientific evidence supporting many plasma transfusion practices is limited and weak. The lack of data, and the absence of authoritative interpretation of the available data, have led to inconsistencies in plasma transfusion practice and raise questions of optimal plasma transfusion strategies to improve patient care and maximize resource utilization.

Practice guidelines (PGs) are systematically developed statements produced to assist practitioners and patients in their decisions about health care for specific clinical circumstances. ${ }^{1}$ Attributes of high-quality PGs include validity, reliability, reproducibility, clinical applicability, multidisciplinary process, review of evidence, and documentation. PGs should be developed using evidencebased medicine (EBM) methods and principles which hold that systematic and explicit approaches in developing guidelines can help protect against errors, resolve disagreements, improve communication of medical information, and thus fulfill needs of all stakeholders (physicians, patients, policy-makers). EBM holds that recommendations for practice should, to the greatest extent possible, be consistent with evidence for or against a given intervention. The first EBM principle is that PG should be informed by systematic reviews (SRs; systematic review refers to the set of techniques and methods that limit bias in the assembly, critical appraisal, and synthesis of all relevant studies on a specific topic). Since evidence is necessary but not sufficient for decision-making, the second EBM principle is to separate assessment of evidence from formulating recommendations when developing PGs.

To improve and standardize plasma transfusion practice, the AABB Board of Directors commissioned the development of evidence-based guidelines according to accepted EBM principles. The GRADE methodology (Grading of Recommendations, Assessment, Development, and Evaluation) was chosen for this process since it is becoming the worldwide standard for formulating evidence-based clinical PGs. ${ }^{2,3}$

To direct this effort, members of the AABB Clinical Transfusion Medicine Committee (CTMC) first developed six questions reflecting common plasma transfusion practices. An SR was performed (see accompanying article ${ }^{4}$ ), and a working group comprising CTMC members along with outside experts representing anesthesiology, hematology, hepatology, and pediatric professional societies as well as the military (see Materials and Methods) analyzed the data from the SR and developed guidance, which is the focus of this manuscript.

\section{MATERIALS AND METHODS}

\section{Panel composition}

A committee composed of 17 members was formed to develop plasma transfusion PGs. Eleven members were representatives of the AABB CTMC (JR, JC, RD, MJD, AE, $\mathrm{MF}, \mathrm{MH}$, JRH, BSS, TS, and JW). Six members were chosen as subject matter experts to represent other professional organizations: American Association for the Study of Liver Diseases (SC), American Academy of Pediatrics (NL), the United States Army (JGP), American Society of Anesthesiology (AS), and American Society of Hematology (ES, CT; shared one vote). Nine of the members were pathologists and/or hematologists, two were anesthesiologists, three were internists, two were pediatricians, and one was a hepatologist. The panel was aided by three consultants who were methodologists: two who performed the SR and one who moderated and assisted the panel in their deliberations to develop these PGs (BD). None of the three consultants voted on the resulting PGs.

\section{Development of six questions to be addressed with guidelines}

The 11 panel members from the CTMC formulated questions that were believed to encompass many of the current pertinent and contentious issues in plasma transfusion. The panelists considered a number of approaches to formulate these questions (e.g., common plasma transfusion practices, practices that use the highest volume of plasma, or plasma transfusion in patient groups with specific diseases [such as liver disease]). Many of the approaches had validity, and it was clear that dozens of different questions could have been constructed to address distinct aspects of plasma transfusion practice. However, after extensive deliberations, the panel unanimously agreed to limit the scope of the present guidelines to six questions that represented the majority of plasma transfusion issues most often discussed between transfusion medicine practitioners and clinicians. The panel believed that addressing these six questions (through guidelines and further 
clinical studies) would significantly improve plasma transfusion practice. Given the limitations of the data in the literature, as described in the SR, it was not possible to address the efficacy of plasma transfusion as a function of underlying coagulation variables in the recipient or to issue evidence-based guidelines addressing plasma dosage. Of note, the use of plasma during plasma exchange was not addressed here since it has recently been subject to detailed examination. ${ }^{5}$

All questions were formulated in the terms of patient groups, intervention (plasma transfusion), and comparator/control treatment (defined in most cases as "no plasma transfusion" for these guidelines). The primary outcome of interest in all cases was mortality. While studies with other comparators were available (e.g., prothrombin complex concentrate), ${ }^{6,7}$ these were considered to be outside the scope of this work. These and other questions remain important areas for future work.

\section{SR}

An SR of the relevant literature, including both randomized controlled and observational studies, was performed (see companion article ${ }^{4}$ ). This SR process utilized a comprehensive literature search, evidence review by a blinded pair of reviewers, exploration of heterogeneity by subgroup, and sensitivity and metaregression methods. The SR also included preparation of the GRADE evidence profiles ${ }^{8}$ summarizing the effect of plasma in various clinical scenarios. The evidence profiles displayed information on the effect of plasma in terms of benefits and harms for the most important clinical outcomes (including death and acute lung injuries). It should be noted that the SR focused on short-term outcomes (up to 30 days) and not longterm outcomes such as viral transmission that may occur after plasma transfusion. The effects were presented in terms of both absolute and relative effect measures. For each question, the evidence profiles were given tentative GRADE-quality criteria for each outcome of importance by the systematic reviewers.

\section{The GRADE methodology for clinical guidelines development (see Appendix)}

The panel's work was directed by the process for guideline development established by the GRADE group. ${ }^{8}$ GRADE is an emerging system for developing PGs, which has been adopted by many professional organizations around the world and increasingly considered as the worldwide standard for formulating evidence-based PGs. ${ }^{9}$

At its core, the GRADE system adheres to the following principles: ${ }^{8-12}$ SRs of the totality of research evidence represent the scientific foundation for development of clinical PGs, and quality of evidence is evaluated separately from the strength of recommendations.
The following factors affect the quality of evidence: 1) study design (randomized clinical trial vs. observational vs. any other types of evidence); 2) methodologic factors that may decrease quality of evidence (inadequate allocation concealment, lack of blinding, large drop-outs, failure to perform intention-to-treat analysis, failure to report outcomes, and stopping early for benefits); 3) factors that may increase quality of evidence (large magnitude of treatment effect, adequate accounting for confounders, and presence of a dose response); ${ }^{12} 4$ ) consistency or inconsistency between the results of published evidence; 5) directness or indirectness of the evidence; 6) precision or imprecision; and 7) reporting bias. ${ }^{11}$ Thus, the quality of evidence represents an estimate of the "correctness" or "truth" of the results obtained in clinical research based on the types of studies performed (e.g., randomized controlled trials or observational studies) as well as the assessment of characteristics of the studies for protection against bias and random error.

Unlike in other guidelines systems, in which quality of evidence is equated with the strength of recommendations, ${ }^{13}$ in the GRADE system the strength of recommendations depends on considerations in addition to the quality of evidence, including tradeoffs between desirable (benefits) and undesirable effects (harms), uncertainty or variability in values and preferences, practice setting, and uncertainty about whether the intervention represents a wise use of resources (costs). ${ }^{10}$ The strength of the recommendation represents the extent to which confidence in an estimate of the effect is adequate to support the recommendation. That is, it is consistent with belief that adherence to a particular recommendation will do more good than harm.

Strong recommendations indicate that most (but perhaps not all) well-informed people would make the same choice. Weak recommendations, in contrast, indicate that while many well-informed people would make that choice, a substantial minority would not. In cases where neither a strong nor a weak recommendation can be agreed upon, no specific recommendation is made, or the use of intervention is endorsed in the context of research.

\section{Development of plasma transfusion guidelines}

Each member of the panel was sent a full copy of the SR along with the GRADE evidence profiles. Each member of the panel was asked to make his or her final judgments on the strength of recommendation and the overall quality of the body of evidence. Voting was anonymous and was based on the use of GRADE grids for formulation of the strength of recommendations. ${ }^{14}$ The panel previously agreed to issue a strong recommendation (e.g., "We recommend ...") if 70\% or more of the panel members voted strongly for (or against) that intervention. A weak recom- 
mendation (e.g., "We suggest . ..") was issued if there were insufficient votes for a strong recommendation, but the total votes strongly and weakly for (or against) the intervention comprised $70 \%$ or more of the panel. If at least $70 \%$ of the panel was neither for nor against an intervention, no recommendation was issued (e.g., "We cannot recommend ....").

\section{PLASMA TRANSFUSION GUIDELINES}

Below, each of the six questions is followed by the panel's recommendations for plasma transfusion in those settings. Supporting background for each of these questions is then presented, followed by a summary of the relevant evidence, potential benefits and harms, and rationale for the panel's recommendations. Detailed descriptions of the studies can be found in the accompanying SR. ${ }^{4}$

\section{Question 1}

Should plasma transfusion (vs. no plasma) be used in trauma patients requiring massive transfusion?

Recommendation: We suggest that plasma be transfused to trauma patients requiring massive transfusion (quality of evidence $=$ moderate).

\section{Question 2}

Should a plasma : red blood cell (RBC) transfusion ratio of $1: 3$ or more (vs. $<1: 3$ ) be used in trauma patients requiring massive transfusion?

Recommendation: We cannot recommend for or against transfusion of plasma at a plasma : $R B C$ ratio of $1: 3$ or more in trauma patients during massive transfusion (quality of evidence $=$ low).

The panel strongly endorsed further testing of plasma: $R B C$ transfusion ratio of 1:3 or more (vs. $<1: 3)$ in the context of well-designed randomized controlled trials.

\section{Background}

Recent observational studies in trauma patients have suggested that increasing the volume of plasma infused during massive transfusion (based on the plasma : RBC ratio) improves patient outcome. These findings have led to changes in clinical practice in some settings. If these results are accurate and generalizable, they would have important benefits for trauma care. However, broad implementation of these changes would also increase plasma usage, raising concerns of resource utilization, and may increase the occurrence of transfusion-related acute lung injury (TRALI) and other adverse effects of plasma transfusion. To our knowledge, these observational studies have not previously been subjected to detailed meta-analysis, and the benefits and risks of this approach have not been carefully weighed by subject matter experts. The committee separately considered two aspects of the practice of plasma infusion during massive transfusion: should plasma be used during massive transfusion and should plasma be transfused at a ratio of 1:3 or more in these settings?

\section{Evidence summary}

We found 10 observational studies (reported in 12 publications) that assessed the effects of plasma : RBC transfusion ratios on mortality in trauma patients experiencing massive transfusion (defined as transfusion of $\geq 10$ units of RBCs). ${ }^{15-26}$ Patients in these studies had severe blunt or penetrating trauma, required urgent surgery, had massive bleeding, and in some cases were acidotic. The experimental group in each of these studies was transfused with plasma at a ratio of 1:3 or more with RBCs; the control groups had ratios lower than in the experimental arms.

In these studies, transfusion of plasma at plasma: $\mathrm{RBC}$ ratios greater than 1:3 (in the range of 1:2.5-1:1) was associated with significant reductions in mortality (odds ratio $[\mathrm{OR}], 0.38$; 95\% confidence interval [CI], 0.24-0.60; $\left.\mathrm{I}^{2}=85 \%\right)$ and a reduced risk of multiorgan failure (OR, 0.40; 95\% CI, 0.26-0.60). ${ }^{4}$ However, because these studies were observational, unintended biases could not be excluded as explanations for improved survival. For example, more resources, including plasma transfusion, may have been expended on the patients deemed most likely to survive, leading to selection bias. Additionally, survivor bias may also have occurred, in which patients that survived longer had more opportunity to receive treatments, including increased volumes of plasma transfusion (thus potentially leading to higher plasma: RBC transfusion ratios). In either case, surviving patients may have coincidentally received more plasma transfusions, unrelated to an effect of plasma transfusion on survival.

\section{Potential benefits}

In trauma patients who require massive transfusion, plasma infusion reduced the death rate by approximately $60 \%$ (OR, 0.38) and also reduced the risk of multiorgan failure by approximately $60 \%(\mathrm{OR}, 0.40)$ in comparison with control. ${ }^{4}$ In both cases, the control event rate was high, which led to a large absolute treatment effect (e.g., four patients needed to be treated with higher plasma : RBC to prevent one death).

\section{Potential harms}

In nontrauma studies evaluated as part of the SR, plasma transfusion was associated with an almost threefold increased risk of acute lung injury (OR, 2.92; 95\% CI, 1.994.29). ${ }^{4}$ Increased use of plasma in massive transfusion patients may also reduce plasma inventories, raising questions of optimal resource utilization. Although increased plasma transfusion may slightly increase the risks of viral transmission, this potential harm was consid- 
ered to be much less significant given that the current risk of transmitting human immunodeficiency virus and hepatitis $\mathrm{C}$ virus, for example, by transfusion is approximately 1 in $2,000,000 .^{27}$

\section{Rationale for recommendations}

Based on the data from these studies and the analysis described, all panel members supported the practice of infusing plasma to trauma patients during massive transfusion; half of the panel strongly supported this practice while half were in weak support (Fig. 1A). None of the panel voted against this practice. Since more than $70 \%$ of the panel was in favor of this practice (but less than $70 \%$ was strongly in favor) a weak recommendation was issued. The majority of the panel believed that the evidence supporting plasma transfusion during massive transfusion was of moderate quality (Fig. 1B). The remainder believed that the evidence was of low or very low quality.

The panel's suggestion to infuse plasma to trauma patients requiring massive transfusion indicates that most practitioners would make the choice to infuse plasma in this setting, although a substantial minority may not. Some panelists who were weakly in favor of this therapy believed that patient-specific circumstances such as the amount of blood lost, the speed with which bleeding was controlled, and the likelihood of ongoing bleeding may influence clinical judgment regarding plasma use in trauma patients. Nonetheless, the committee's suggestion to transfuse plasma means that the benefits of this therapy likely outweigh the potential harms for most trauma patients.

Half of the panel was weakly in favor of using a plasma : RBC ratio of $1: 3$ or more in this setting (Fig. 2A). However, only one panelist was strongly in favor of this practice, and in total less than $70 \%$ of the panel voted for using this ratio. Thus, no recommendation could be issued. In contrast to the first question, only $25 \%$ of the panel believed that the evidence addressing the plasma : $\mathrm{RBC}$ ratio was of moderate quality, while the remainder considered the evidence to be either low or very low in quality (Fig. 2B). A number of issues were raised that negatively impacted the quality assessments: all of the studies were observational, the patient groups were heterogeneous, the plasma : RBC ratios varied between studies, and potentially significant confounding biases could not be excluded. In addition, panel members believed that the relative weakness of the data did not support the increased utilization of plasma, or increased potential risk of acute lung injury, if a ratio of at least 1:3 were broadly implemented. Finally, there was concern that a stronger recommendation would prevent performance of randomized clinical trials to address this issue more carefully. The panel vote in fact established equipoise, justifying randomized controlled trials in trauma patients where the interventional arm would be transfused with plasma at a ratio of at least 1:3 with RBCs.

\section{Question 3}

Should plasma transfusion (vs. no plasma) be used in surgical and/or trauma patients in the absence of massive transfusion?

Recommendation: We cannot recommend for or against transfusion of plasma for patients undergoing surgery in the absence of massive transfusion (quality of evidence $=$ very low).

\section{Background}

Plasma transfusions are commonly ordered during surgery or other invasive procedures. Most of these transfusions do not occur during massive transfusion episodes
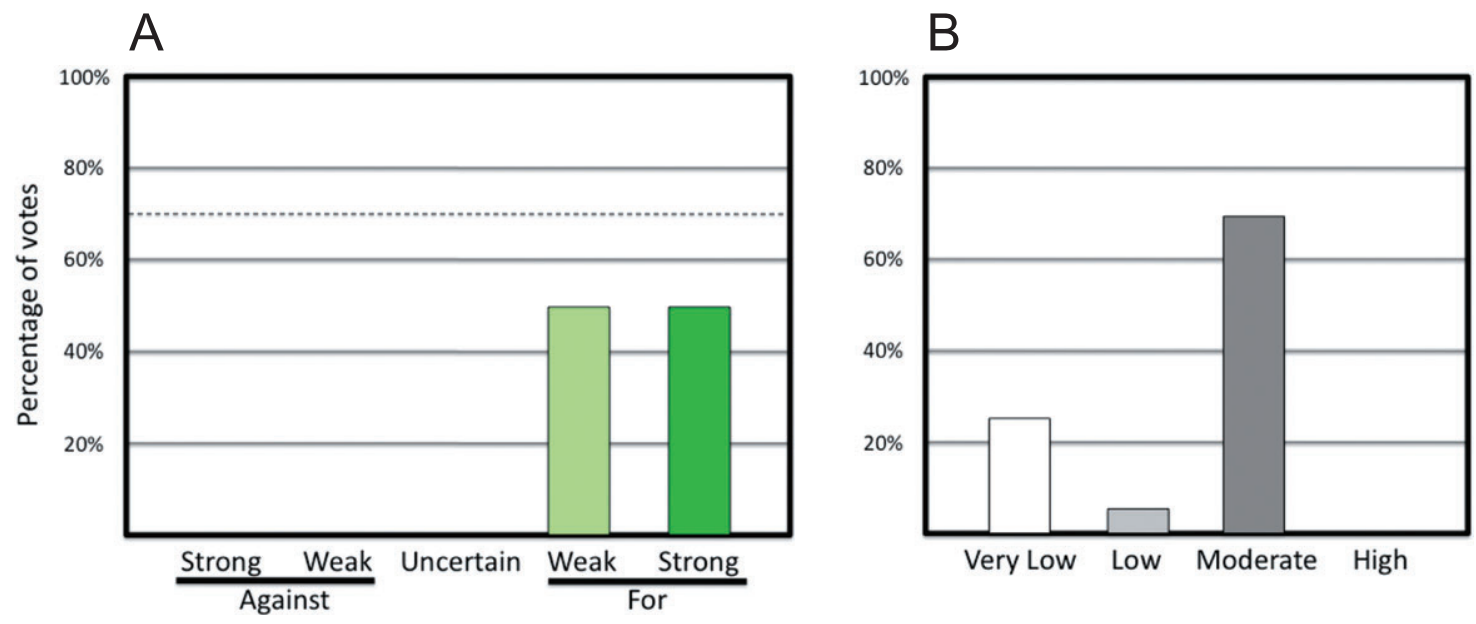

Fig. 1. Should plasma transfusion (vs. no plasma) be used in trauma patients requiring massive transfusion? (A) Percentage of panel recommending for or against this intervention. (B) Quality of evidence supporting this intervention, as rated by the panel. The dotted line in (A) denotes the $70 \%$ threshold. 

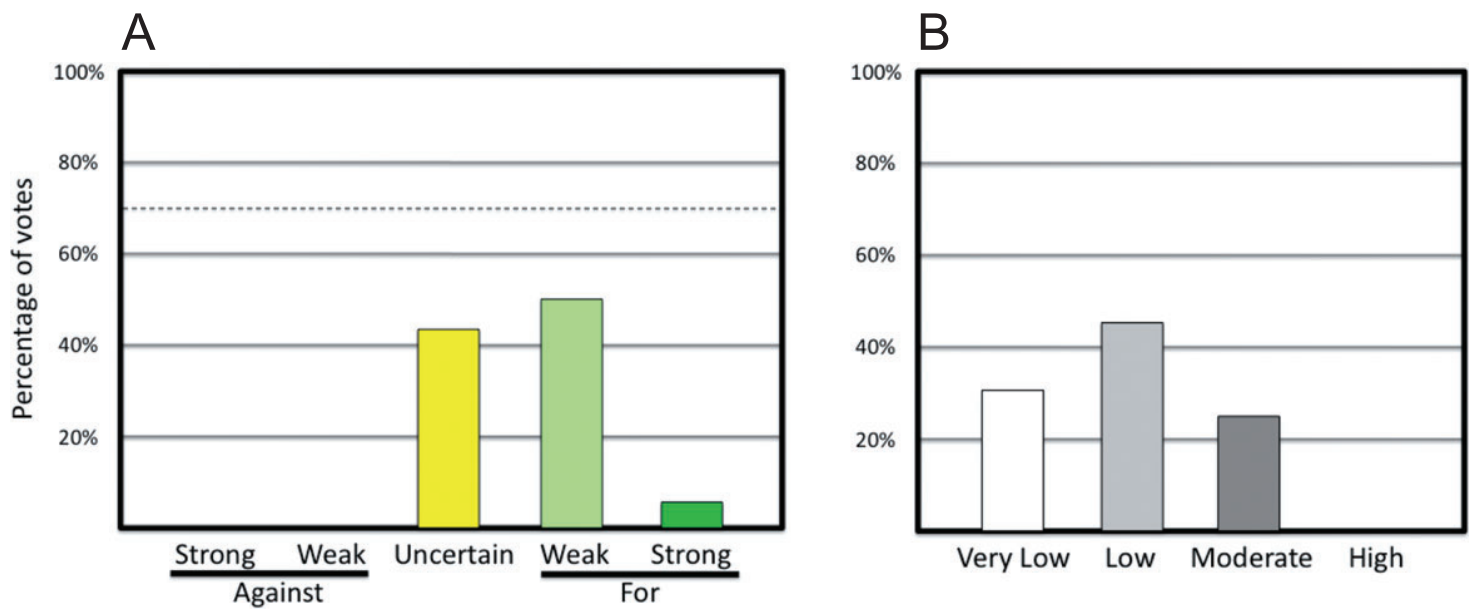

Fig. 2. Should a plasma : RBC transfusion ratio of $1: 3$ or more (vs. $<1: 3)$ be used in trauma patients requiring massive transfusion? (A) Percentage of panel recommending for or against this intervention. (B) Quality of evidence supporting this intervention, as rated by the panel.

(i.e., transfusion of $<10 \mathrm{RBC}$ units), and many are ordered prophylactically in the absence of bleeding. Given the risks associated with plasma transfusion, the panel believed that it was important to define acceptable plasma transfusion practices in this patient population.

\section{Evidence summary}

Twelve studies reported mortality in patients undergoing surgery in settings other than trauma and massive transfusion, although six reported no deaths and did not contribute to the analysis. ${ }^{28-39}$ Plasma was given to these patients in association with RBC transfusion to replace perioperative blood loss after elective abdominal, orthopedic, urologic, and vascular surgeries; esophagectomy for esophageal cancer; and intraoperatively during liver transplantation. No studies of nonsurgical invasive procedures met inclusion criteria. Only one study was randomized, although it did not clearly conceal allocation. ${ }^{30}$ Some of the observational studies did not control for potential confounders making inference about causality challenging. ${ }^{22,38}$ Meta-analysis of these studies shows that plasma transfusion was associated with a trend toward increased risk of death $\left(\mathrm{OR}, 1.22 ; 95 \% \mathrm{CI}, 0.73-2.03 ; \mathrm{I}^{2}=61 \%\right)$ which, however, fell short of significance. ${ }^{4}$

\section{Potential benefits}

In these studies, there were no obvious benefits of plasma transfusion, such as lower mortality, less bleeding, reduced blood loss and blood product usage, or reduced rates of myocardial infarction and stroke.

\section{Potential harms}

Plasma transfusions in these patients was associated with a trend toward increased mortality and as described above is also associated with an increased rate of lung injury.
Additionally, transfusion of plasma to patients who do not require it raises issues of resource utilization.

\section{Rationale for recommendation}

Despite the widespread use of plasma in patients undergoing surgery or other invasive procedures in the absence of massive transfusion, $69 \%$ of the panel recommended against this practice based on the available evidence including the trend toward increased risk of death in this patient population and the known risks of TRALI with plasma transfusion (Fig. 3A). Half the panel was weakly against this practice, while $19 \%$ was strongly opposed. The remaining $31 \%$ of the panel was uncertain whether plasma should be transfused to these patients in part because the evidence was too weak (Fig. 3B) to supersede clinical judgments regarding the need for plasma in individual patients. On the other hand, no panelist voted for plasma transfusion, drawing into question the appropriateness of this practice in surgical patients without massive hemorrhage. Nonetheless, since less than $70 \%$ of the panel in total voted against this practice, the panel could not issue a recommendation for or against plasma transfusion in these patients. More than $80 \%$ of the panel believed that the evidence addressing this practice was of very low quality, while the remainder evaluated the evidence as low quality (Fig. 3B).

\section{Question 4}

Should plasma transfusion (vs. no plasma) be used for patients with warfarin anticoagulation-related intracranial hemorrhage?

Recommendation: We suggest that plasma be transfused in patients with warfarin anticoagulation-related intracranial hemorrhage (quality of evidence $=\mathbf{l o w}$ ). 

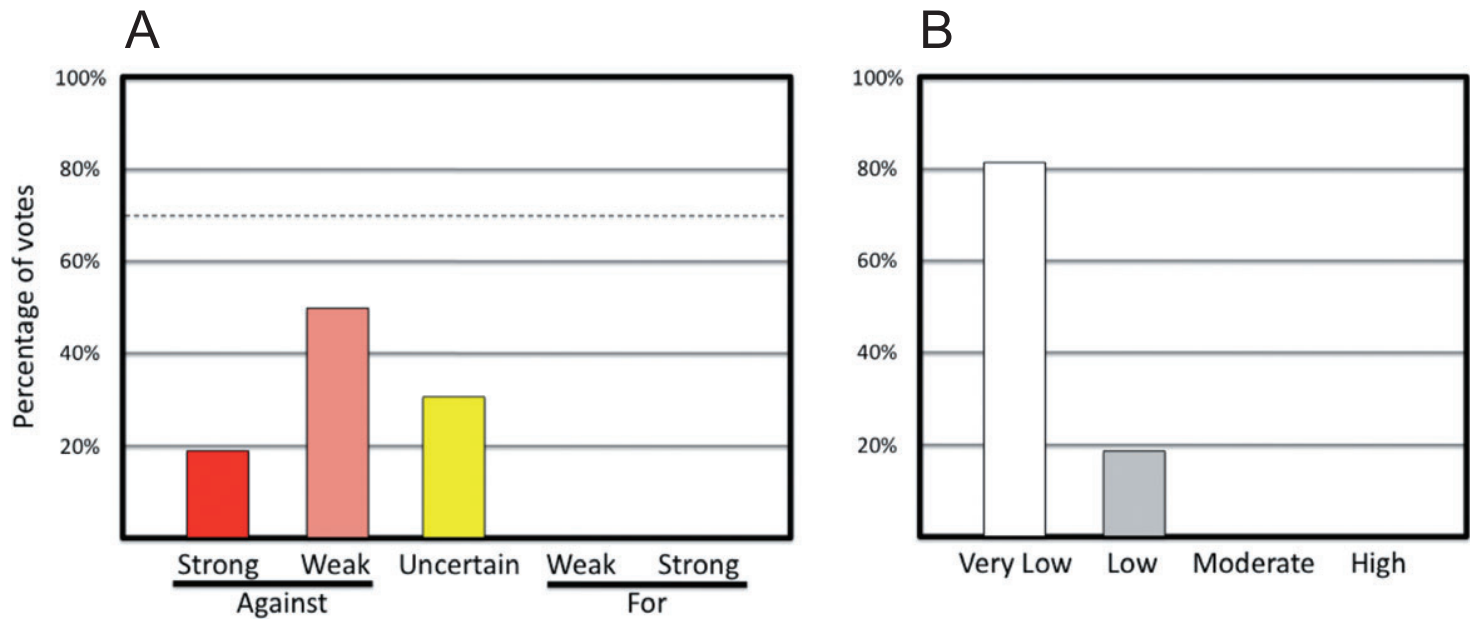

Fig. 3. Should plasma transfusion (vs. no plasma) be used in surgical and/or trauma patients in the absence of massive transfusion? (A) Percentage of panel recommending for or against this intervention. (B) Quality of evidence supporting this intervention, as rated by the panel.

\section{Question 5}

Should plasma transfusion (vs. no plasma) be used to reverse warfarin anticoagulation in patients without intracranial hemorrhage?

Recommendation: We cannot recommend for or against transfusion of plasma to reverse warfarin in patients without intracranial hemorrhage (quality of evidence $=$ very low .

\section{Background}

In patients on warfarin therapy, significant coagulopathies may occur that can have life-threatening consequences, including closed-space bleeding such as intracranial hemorrhage. Vitamin K injection is often used to reverse warfarin therapy. Alternatively, plasma transfusion can be used for more rapid warfarin reversal, although the potential benefits of this therapy must be closely weighed against the risks.

\section{Evidence summary}

We identified two observational studies and one randomized controlled trial that reported mortality in patients on oral anticoagulation who were transfused with plasma (although the randomized controlled trial had no mortality events and so did not contribute to the analysis). ${ }^{40-42}$ Only one of these studies, a retrospective analysis, quantified the occurrence of intracranial hemorrhage. In this study, transfusions of 300 to $600 \mathrm{~mL}$ of plasma were associated with a significant reduction in mortality (OR, 0.29; 95\% CI, 0.09-0.98), ${ }^{4}$ but was subject to confounding and reported a small number of events.

\section{Potential benefits}

In a retrospective study, plasma transfusion (300$600 \mathrm{~mL}$ ) reduced mortality in patients with warfarin anticoagulation-related intracranial hemorrhage. Plasma transfusion did not affect mortality in nonbleeding patients with an international normalized ratio of 2.5-2.7.

\section{Potential harms}

As previously described, more frequent plasma transfusions would be expected to increase the occurrence of acute lung injury and reduce plasma inventory.

\section{Rationale for recommendation}

Eighty-seven percent of the panel voted for plasma transfusion in warfarin-treated patients with intracranial hemorrhage (Fig. 4A), although the vast majority of these panelists were weakly in favor. Thus, the panel issued a weak recommendation in favor of plasma transfusion in this scenario. Half of the panel members believed that the evidence was of low quality, while others viewed it as either very low or moderate in quality. One panelist considered the evidence to be of high quality (Fig. 4B). Despite general concerns with evidence quality, the panel believed that the efficacy of plasma to reduce mortality outweighed its potential risks in warfarin-treated patients with intracranial hemorrhage.

In contrast, $62 \%$ of panelists voted against plasma transfusion if warfarin-treated patients did not have intracranial hemorrhage (Fig. 5A). The remaining panel members were uncertain as to whether plasma should be transfused to these patients or not. Given that the percentage of the panel opposed to this practice did not reach 

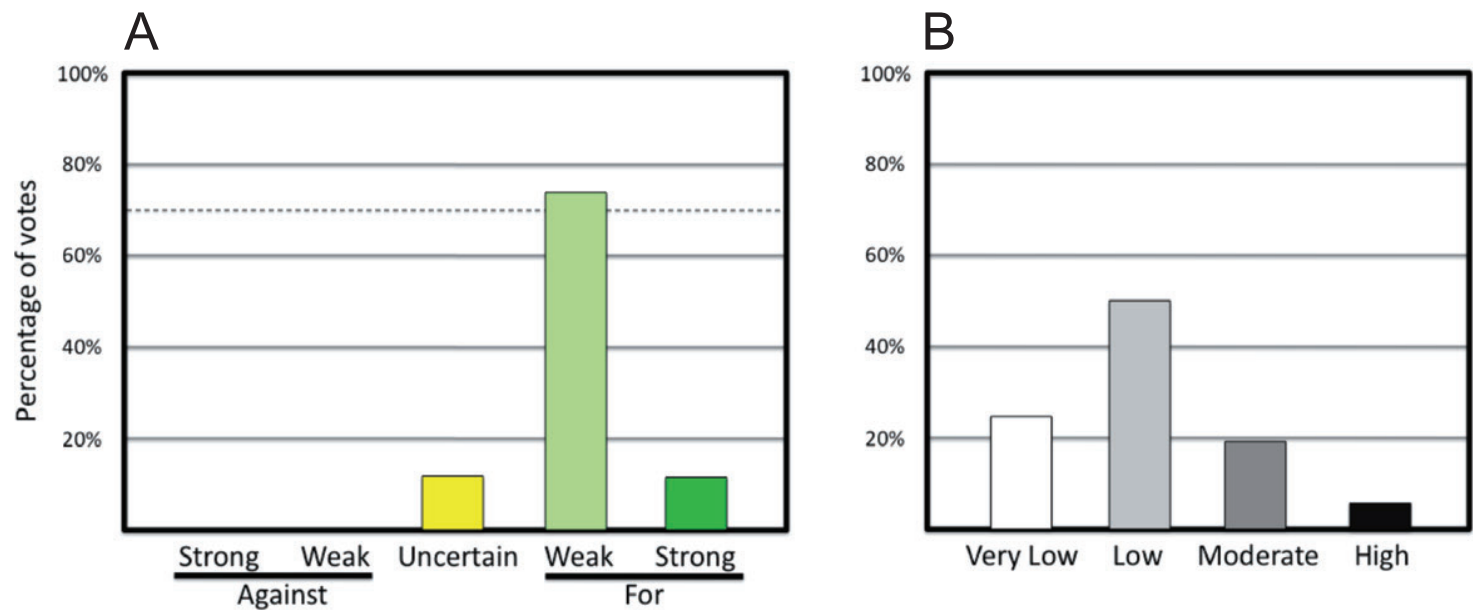

Fig. 4. Should plasma transfusion (vs. no plasma) be used for patients with warfarin anticoagulation-related intracranial hemorrhage? (A) Percentage of panel recommending for or against this intervention. (B) Quality of evidence supporting this intervention, as rated by the panel.
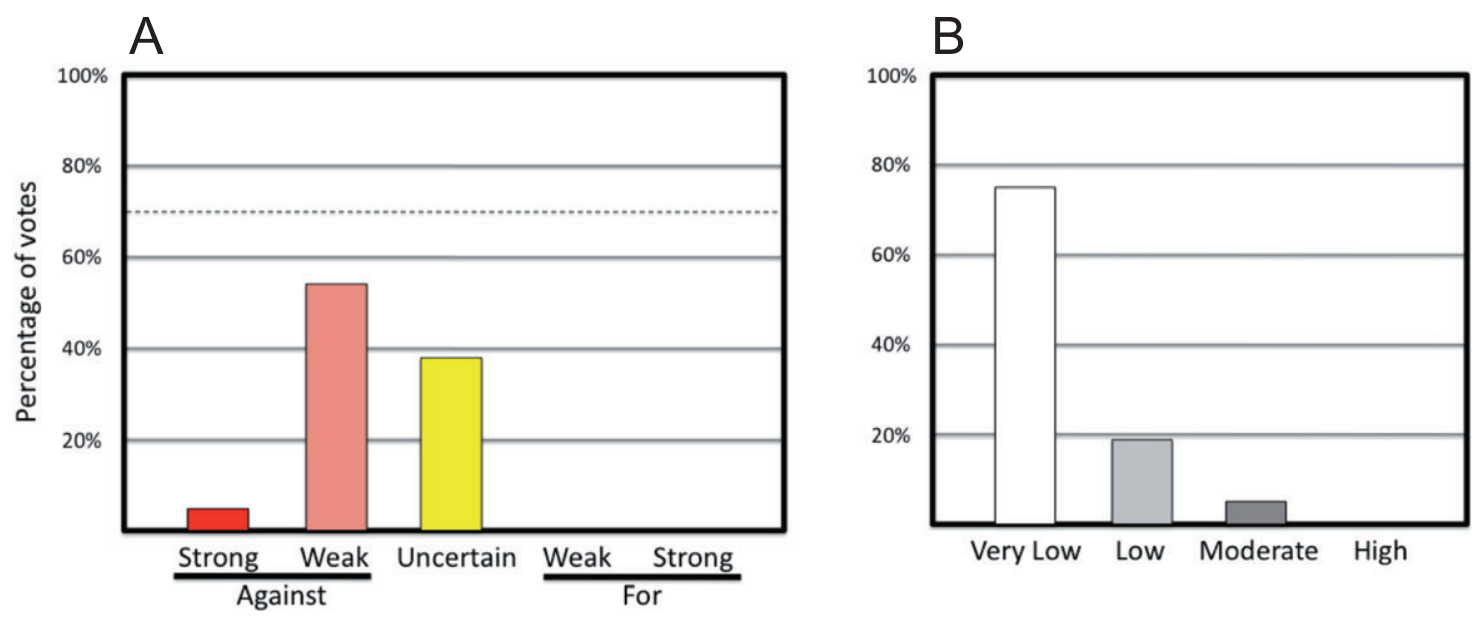

Fig. 5. Should plasma transfusion (vs. no plasma) be used to reverse warfarin anticoagulation in patients without intracranial hemorrhage? (A) Percentage of panel recommending for or against this intervention. (B) Quality of evidence supporting this intervention, as rated by the panel.

$70 \%$, no recommendation was issued. Seventy-five percent of the panel believed that the evidence for this indication was of very low quality (Fig. 5B). This group of patients includes those with other forms of hemorrhage, such as gastrointestinal bleeding. However, it should be noted that no clinical studies were identified that specifically addressed the efficacy of plasma transfusion in these other patient groups. Well-designed studies that directly evaluated the use of plasma transfusion in patients with other forms of hemorrhage could potentially alter this recommendation.

Of note, the eighth edition of the American College of Chest Physicians (ACCP) Evidence-Based Clinical Practice Guidelines also assessed that the quality of evidence as low related to the scenario of life-threatening bleeding (e.g., intracranial hemorrhage) during warfarin therapy, but made a strong recommendation for administrating intravenous vitamin $\mathrm{K}$ along with plasma, prothrombin complex concentrate, or Factor VIIa. ACCP makes no mention of the use of plasma in the patient who is not bleeding; instead, the ACCP panel recommends either monitoring (after warfarin is omitted) or administration of vitamin $\mathrm{K}^{43}$

\section{Question 6}

Should plasma transfusion (vs. no plasma) be used in other groups of patients (e.g., in the absence of massive transfusion, surgery, bleeding, or overanticoagulation)?

Recommendation: We suggest against plasma transfusion in other groups for which data were available (acute pancreatitis, organophosphate poisoning, coagulopathy 

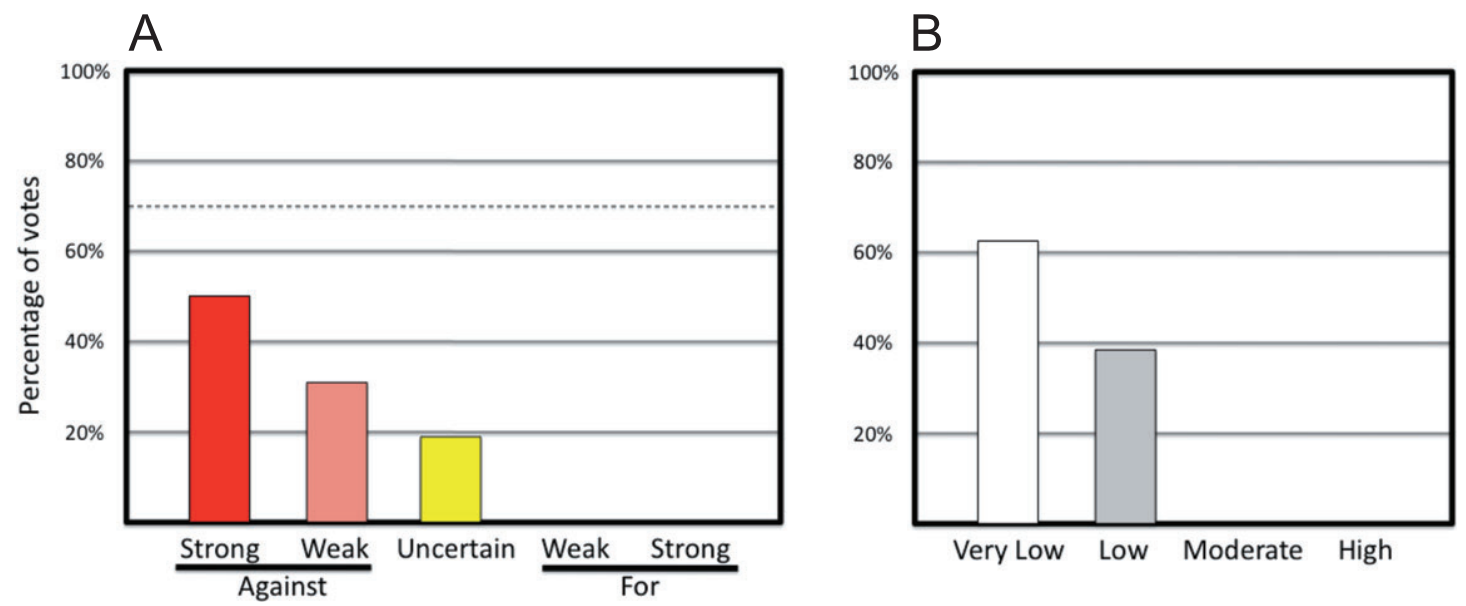

Fig. 6. Should plasma transfusion (vs. no plasma) be used in other groups of patients (e.g., in the absence of massive transfusion, surgery, bleeding, or overanticoagulation)? (A) Percentage of panel recommending for or against this intervention. (B) Quality of evidence supporting this intervention, as rated by the panel.

associated with acetaminophen overdose, intracranial hemorrhage after severe closed head injury in patients without coagulopathy, nonsurgical noncardiac patients in the intensive care unit; quality of evidence = very low).

\section{Background}

In addition to the scenarios described, plasma transfusions are often ordered for other diverse indications including correction of abnormal coagulation tests, prophylactic prevention of future bleeding, acetaminophen overdose, organophosphate poisoning, and volume replacement. In many of these cases, the adverse effects of plasma transfusion may outweigh any potential benefits.

\section{Evidence summary}

Six relevant studies with heterogeneous populations were identified in which plasma was transfused for the treatment of acute pancreatitis, organophosphate poisoning, and coagulopathy associated with acetaminophen overdose; to prevent intracranial hemorrhage after severe closed head injury in patients without coagulopathy; and to critically ill nonsurgical noncardiac patients in an intensive care unit. ${ }^{44-49}$ Given the heterogeneity of these studies, they were not subject to meta-analysis. When these studies were separated into subgroups according to the indication for plasma administration, plasma did not impact mortality except in the two studies in which it was given prophylactically without coagulopathy; ${ }^{47,48}$ in this setting, plasma transfusion was associated with increased mortality (OR, 2.00; 95\% CI, 1.11-3.59). ${ }^{4}$

\section{Potential benefits}

In these studies, there were no obvious benefits of plasma transfusion.

\section{Potential harms}

In addition to the risk of acute lung injury, and the reduction of plasma inventory with inappropriate use, plasma significantly increased mortality in two studies in which it was given prophylactically in the absence of coagulopathy.

\section{Rationale for recommendation}

Fifty percent of the panel was strongly against this practice, and the total votes strongly or weakly opposed accounted for $81 \%$ of the panel (Fig. 6A). Thus, a weak recommendation was issued against plasma transfusion in these patients. The quality of evidence was considered to be either very low ( $62 \%$ of panel) or low (38\%; Fig. $6 \mathrm{~B})$.

\section{DISCUSSION}

Plasma transfusions are a frequently prescribed intervention, yet minimal guidance is available to clinicians to direct its proper use. If high-quality plasma transfusion PGs were available, they may improve patient outcomes, improve clinical practice, minimize inappropriate practice variation, provide decision support tools for practitioners and points of reference for medical orientation and education, and provide criteria for self-evaluation and assistance with reimbursement and coverage decisions. The AABB has undertaken an effort to develop evidencebased PGs governing the transfusion of major blood components, beginning with transfusion of plasma.

During this process, a comprehensive SR of the available literature showed that the data from clinical studies addressing plasma transfusion practices were sparse, typically of low quality, and often did not address important practices (e.g., plasma transfusion for nonsurgical 
invasive procedures). Given the limitations of the underlying data, only relatively weak recommendations (e.g., "We suggest that plasma be transfused to trauma patients requiring massive transfusion") could be issued regarding many of the common plasma transfusion practices. In the GRADE system, weak recommendations of this sort indicate that while many well-informed people would make the same choice, a substantial minority would not.,10 Despite the fact that these were weak recommendations, we believe that they will be useful to clinicians making plasma transfusion decisions. However, it is important for medical practitioners to understand that AABB considers adherence to these guidelines to be voluntary and that guidelines cannot always account for individual variation among patients. They are not intended to supplant physician judgment with respect to particular patients or special clinical situations.

For other clinical scenarios (plasma: $\mathrm{RBC}$ ratio in massive transfusion, plasma transfusion in surgery without massive transfusion, warfarin reversal in the absence of intracranial hemorrhage), insufficient data were available for the panel to issue PGs. Even in these cases, however, clinicians may find the discussion of the relative benefits and harms of plasma therapy, as well as the panel voting results, to be of assistance when treating similar types of patients.

As an additional benefit of the guidelines development process, the review and synthesis of the latest literature on plasma transfusion has served to identify persistent areas of uncertainty as well as important questions for further research. For example, for trauma patients undergoing massive transfusion the optimal plasma : RBC ratio of transfused blood products represents a significant remaining question. The panel believed that clinical trials that randomized trauma patients to receive plasma at defined ratios to RBCs would be useful to solidify these recommendations. The panel was also surprised to find that there were not more high-quality studies addressing the use of plasma transfusion in patients undergoing surgery or nonsurgical interventional procedures or experiencing coagulopathy related to other causes. The studies that were available utilized heterogeneous populations, making meta-analysis difficult.

While many physicians transfuse plasma based on coagulation testing (e.g., prothrombin time and international normalized ratio), data from the available clinical studies did not allow outcomes of plasma transfusion to be correlated with differences in the degree of coagulopathy. Additionally, there were insufficient data to recommend an appropriate plasma dose for most of the clinical indications that were studied. Future investigations of plasma transfusion should be designed to address these deficiencies.

In summary, we have systematically developed evidence-based guidance to inform plasma transfusion decisions in common clinical scenarios. We believe that this is an important step toward optimizing transfusion outcomes and resource utilization by thorough analysis of the relevant clinical data. In the future, the availability of additional randomized studies addressing many of the common plasma transfusion situations should allow the development of more comprehensive and definitive guidance for plasma transfusion.

\section{Disclaimer}

While well-constructed evidence-based PGs provide valuable assistance to practitioners and patients making health care decisions, it is important to realize that guidelines cannot always account for individual variation among patients. They are not intended to supplant physician judgment with respect to particular patients or special clinical situations. Accordingly, AABB considers adherence to these guidelines to be voluntary, with the ultimate determination regarding their application to be made by the physician in the light of each patient's individual circumstances. Furthermore, these guidelines cannot be assumed to apply to interventions performed in clinical trials, which are designed to test differing interventions in a disease for which better management is needed. Since PG development involves a review and synthesis of the latest literature, PGs also serve to identify gaps in the existing knowledge and important questions for further research and those settings in which alternative therapies should be considered.

\section{APPENDIX: GRADE DEFINITIONS}

A) Quality of evidence represents the extent of confidence that an estimate of effect is correct, that is, representing the "truth."

Quality of evidence is rated as:

- High: Considerable confidence in the estimate of effect. Future research is unlikely to change the estimate of the health intervention's effect.

- Moderate: Further research is likely to have an important impact on confidence in the estimate and may change the estimate of the health intervention's effect.

- Low: Further research is very likely to have an important impact on our confidence in the estimate of effect and is likely to change the estimate.

- Very low: Any estimate of effect is very uncertain.

B) Strength of recommendation according to GRADE is defined as the extent to which confidence in an estimate of the effect is adequate to support recommendations; that is, it is consistent with belief that adherence to a particular recommendation will do more good than harm. 
Strength of recommendation (for or against particular intervention) is graded as:

- Strong: indicating the judgment that most wellinformed people will make the same choice. The terminology "We recommend..." is used for these situations.

- Weak: indicating the judgment that a majority of well-informed people will make the same choice, but a substantial minority will not. The terminology "We suggest ...." is used in these situations.

- Uncertain: indicating that the panel made no specific recommendations for or against interventions or made recommendations only in the context of research. In these cases, we phrased the recommendations as "We cannot recommend for or against ..."

As long as there is judgment that benefits outweigh the harms, recommendation can be strong even if the quality of evidence is low or very low.

C) Determinants of the strength of recommendations

\begin{tabular}{|c|c|}
\hline $\begin{array}{l}\text { Factors that can } \\
\text { strengthen a } \\
\text { recommendation }\end{array}$ & Comment \\
\hline $\begin{array}{l}\text { Quality of } \\
\text { evidence }\end{array}$ & $\begin{array}{l}\text { The higher the quality of evidence, } \\
\text { the more likely a strong } \\
\text { recommendation will be made. }\end{array}$ \\
\hline $\begin{array}{l}\text { Balance between } \\
\text { desirable and } \\
\text { undesirable } \\
\text { effects }\end{array}$ & $\begin{array}{l}\text { The larger the difference between } \\
\text { the desirable and undesirable } \\
\text { consequences, the more likely a } \\
\text { strong recommendation is } \\
\text { warranted. The smaller the net } \\
\text { benefit, and the lower the certainty } \\
\text { of that benefit, the more likely a } \\
\text { weak recommendation will be } \\
\text { made. }\end{array}$ \\
\hline $\begin{array}{l}\text { Values and } \\
\text { preferences }\end{array}$ & $\begin{array}{l}\text { The greater the variability in values } \\
\text { and preferences, or the more } \\
\text { uncertain the values and } \\
\text { preferences, the more likely a weak } \\
\text { recommendation is warranted. }\end{array}$ \\
\hline $\begin{array}{l}\text { Costs (resource } \\
\text { allocation) }\end{array}$ & $\begin{array}{l}\text { The higher the costs of an } \\
\text { intervention-that is, the more } \\
\text { resources consumed-the less } \\
\text { likely a strong recommendation is } \\
\text { warranted. }\end{array}$ \\
\hline
\end{tabular}

\section{ACKNOWLEDGMENT}

This work was completely funded by the AABB.

\section{CONFLICT OF INTEREST}

JDR had full access to all of the data in the study, takes responsibility for the integrity of the data and the accuracy of the data analysis, and participated in the conception, design, acquisition of data, analysis and interpretation of data; drafting of the manuscript; and critical revision of the manuscript for important intellectual content. No conflicts. SC, JC, RD, MJD, AE, MF, MH, JRH, NL, JGP, BSS, AS, TS, ES, CT, and JW participated in the conception, design, analysis, and interpretation of data and critical revision of the manuscript for important intellectual content. No conflicts. BD participated in the conception, design, and acquisition of data; analysis and interpretation of data; drafting of the manuscript; and critical revision of the manuscript for important intellectual content. No conflicts.

\section{REFERENCES}

1. Guidelines for clinical practice: from development to use. Washington, DC: National Academy Press; 1992.

2. Schunemann HJ, Oxman AD, Brozek J, Glasziou P, Jaeschke R, Vist GE, Williams JW Jr, Kunz R, Craig J, Montori VM, Bossuyt P, Guyatt GH; GRADE Working Group. Grading quality of evidence and strength of recommendations for diagnostic tests and strategies. BMJ 2008;336: 1106-10.

3. Guyatt GH, Oxman AD, Vist GE, Kunz R, Falck-Ytter Y, Alonso-Coello P, Schünemann HJ; GRADE Working Group. GRADE: an emerging consensus on rating quality of evidence and strength of recommendations. BMJ 2008;336:924-6.

4. Murad MH, Stubbs JR, Gandhi MJ, Wang AT, Paul A, Erwin PJ, Montori VM, Roback JD. The effect of plasma transfusion on morbidity and mortality: a systematic review and meta-analysis. Transfusion 2010;50:1370-83.

5. Szczepiorkowski ZM, Bandarenko N, Kim HC, Linenberger ML, Marques MB, Sarode R, Schwartz J, Shaz BH, Weinstein R, Wirk A, Winters JL; American Society for Apheresis; Apheresis Applications Committee of the American Society for Apheresis. Guidelines on the use of therapeutic apheresis in clinical practice: evidence-based approach from the Apheresis Applications Committee of the American Society for Apheresis. J Clin Apher 2007;22:106-75.

6. Mannucci PM, Franchi F, Dioguardi N. Correction of abnormal coagulation in chronic liver disease by combined use of fresh-frozen plasma and prothrombin complex concentrates. Lancet 1976;2:542-5.

7. Boughton BJ, Simpson A, Baar S, Ala F, Casson J, Gower J. The concentration of plasma fibronectin in burns patients treated with fresh frozen plasma or plasma protein fraction. Resuscitation 1984;12:41-5.

8. GRADE Working Group. Grading quality of evidence and strength of recommendations. BMJ 2004;328:1490-8.

9. Guyatt GH, Oxman AD, Vist GE, Kunz R, Falck-Ytter Y, Alonso-Coello P, Schünemann HJ; GRADE Working Group. GRADE: an emerging consensus on rating quality of evidence and strength of recommendations. BMJ 2008;336: 924-6.

10. Guyatt GH, Oxman AD, Kunz R, Falck-Ytter Y, Vist GE, 
Liberati A, Schünemann HJ; GRADE Working Group. Going from evidence to recommendations. BMJ 2008;336:1049-51.

11. Guyatt GH, Oxman AD, Kunz R, Jaeschke R, Helfand M, Liberati A, Vist GE, Schünemann HJ; GRADE Working Group. Incorporating considerations of resources use into grading recommendations. BMJ 2008;336:1170-3.

12. Guyatt GH, Oxman AD, Kunz R, Vist GE, Falck-Ytter Y, Schunemann HJ. What is "quality of evidence" and why is it important to clinicians? BMJ 2008;336:995-8.

13. West S, King V, Carey TS, Lohr KN, McKoy N, Sutton SF, Lux L. Systems to rate the strength of scientific evidence. Evidence Report/Technology Assessment No. 47. Rockville (MD): Agency for Health Care Research and Quality; 2002.

14. Jaeschke R, Guyatt GH, Dellinger P, Schünemann H, Levy MM, Kunz R, Norris S, Bion J; GRADE Working Group. Use of GRADE grid to reach decisions on clinical practice guidelines when consensus is elusive. BMJ 2008;337.

15. Borgman MA, Spinella PC, Perkins JG, Grathwohl KW, Repine T, Beekley AC, Sebesta J, Jenkins D, Wade CE, Holcomb JB. The ratio of blood products transfused affects mortality in patients receiving massive transfusions at a combat support hospital. J Trauma 2007;63:805-13.

16. Cotton BA, Gunter OL, Isbell J, Au BK, Robertson AM, Morris JA Jr, St Jacques P, Young PP. Damage control hematology: the impact of a trauma exsanguination protocol on survival and blood product utilization. J Trauma 2008;64:1177-82; discussion 1182-73.

17. Cotton BA, Jerome R, Collier BR, Khetarpal S, Holevar M, Tucker B, Kurek S, Mowery NT, Shah K, Bromberg W, Gunter OL, Riordan WP Jr; Eastern Association for the Surgery of Trauma Practice Parameter Workgroup for Prehospital Fluid Resuscitation. Guidelines for prehospital fluid resuscitation in the injured patient. J Trauma 2009;67: 389-402.

18. Gunter OL Jr, Au BK, Isbell JM, Mowery NT, Young PP, Cotton BA. Optimizing outcomes in damage control resuscitation: identifying blood product ratios associated with improved survival. J Trauma 2008;65:527-34.

19. Holcomb JB, Wade CE, Michalek JE, Chisholm GB, Zarzabal LA, Schreiber MA, Gonzalez EA, Pomper GJ, Perkins JG, Spinella PC, Williams KL, Park MS. Increased plasma and platelet to red blood cell ratios improves outcome in 466 massively transfused civilian trauma patients. Ann Surg 2008;248:447-58.

20. Kashuk JL, Moore EE, Johnson JL, Haenel J, Wilson M, Moore JB, Cothren CC, Biffl WL, Banerjee A, Sauaia A. Postinjury life threatening coagulopathy: is 1:1 fresh frozen plasma : packed red blood cells the answer? J Trauma 2008;65:261-70; discussion 270-61.

21. Maegele M, Lefering R, Paffrath T, Tjardes T, Simanski C, Bouillon B. Red-blood-cell to plasma ratios transfused during massive transfusion are associated with mortality in severe multiple injury: a retrospective analysis from the Trauma Registry of the Deutsche Gesellschaft fur Unfallchirurgie. Vox Sang 2008;95:112-9.
22. Scalea TM, Bochicchio KM, Lumpkins K, Hess JR, Dutton R, Pyle A, Bochicchio GV. Early aggressive use of fresh frozen plasma does not improve outcome in critically injured trauma patients. Ann Surg 2008;248:578-84.

23. Dente CJ, Shaz BH, Nicholas JM, Harris RS, Wyrzykowski AD, Patel S, Shah A, Vercruysse GA, Feliciano DV, Rozycki GS, Salomone JP, Ingram WL. Improvements in early mortality and coagulopathy are sustained better in patients with blunt trauma after institution of a massive transfusion protocol in a civilian level I trauma center. J Trauma 2009; 66:1616-24.

24. Snyder CW, Weinberg JA, McGwin G Jr, Melton SM, George RL, Reiff DA, Cross JM, Hubbard-Brown J, Rue LW 3rd, Kerby JD. The relationship of blood product ratio to mortality: survival benefit or survival bias? J Trauma 2009; 66:358-62; discussion 362-54.

25. Teixeira PG, Inaba K, Shulman I, Salim A, Demetriades D, Brown C, Browder T, Green D, Rhee P. Impact of plasma transfusion in massively transfused trauma patients. J Trauma 2009;66:693-7.

26. Duchesne JC, Hunt JP, Wahl G, Marr AB, Wang YZ, Weintraub SE, Wright MJ, McSwain NE Jr. Review of current blood transfusions strategies in a mature level I trauma center: were we wrong for the last 60 years? J Trauma 2008; 65:272-6; discussion 276-8.

27. Dodd RY, Notari EP, Stramer SL. Current prevalence and incidence of infectious disease markers and estimated window-period risk in the American Red Cross blood donor population. [comment]. Transfusion 2002;42:975-9.

28. Wilhelmi M, Franke U, Cohnert T, Weber P, Kaukemüller J, Fischer S, Wahlers T, Haverich A. Coronary artery bypass grafting surgery without the routine application of blood products: is it feasible? Eur J Cardiothorac Surg 2001;19: 657-61.

29. Gajic O, Rana R, Mendez JL, Rickman OB, Lymp JF, Hubmayr RD, Moore SB. Acute lung injury after blood transfusion in mechanically ventilated patients. Transfusion 2004;44:1468-74.

30. Hedstrand U, Hogman C, Zaren B, Lundkvist B. Postoperative complications after blood replacement with or without plasma. A trial in elective surgery. Acta Chir Scand 1987; 153:501-5.

31. Massicotte L, Sassine MP, Lenis S, Seal RF, Roy A. Survival rate changes with transfusion of blood products during liver transplantation. Can J Anaesth 2005;52:148-55.

32. Swisher SG, Holmes EC, Hunt KK, Gornbein JA, Zinner MJ, McFadden DW. Perioperative blood transfusions and decreased long-term survival in esophageal cancer. J Thorac Cardiovasc Surg 1996;112:341-8.

33. Jawan B, de Villa V, Luk HN, Chen YS, Chiang YC, Wang CC, Wang SH, Cheng YF, Huang TL, Eng HL, Liu PP, Chen CL. Ionized calcium changes during living-donor liver transplantation in patients with and without administration of blood-bank products. Transpl Int 2003;16:510-4.

34. Sano T, Shimada K, Sakamoto Y, Yamamoto J, Yamasaki S, 
Kosuge T. One hundred two consecutive hepatobiliary resections for perihilar cholangiocarcinoma with zero mortality. Ann Surg 2006;244:240-7.

35. Martin RC 2nd, Jarnagin WR, Fong Y, Biernacki P, Blumgart LH, DeMatteo RP. The use of fresh frozen plasma after major hepatic resection for colorectal metastasis: is there a standard for transfusion? J Am Coll Surg 2003;196: 402-9.

36. van der Werff YD, van der Houwen HK, Heijmans PJ, Duurkens VA, Leusink HA, van Heesewijk HP, de Boer A. Postpneumonectomy pulmonary edema. A retrospective analysis of incidence and possible risk factors. Chest 1997; 111:1278-84.

37. Kasper SM, Giesecke T, Limpers P, Sabatowski R, Mehlhorn U, Diefenbach C. Failure of autologous fresh frozen plasma to reduce blood loss and transfusion requirements in coronary artery bypass surgery. Anesthesiology 2001;95: 81-6; discussion 86A.

38. Ranucci M, Pazzaglia A, Bianchini C, Bozzetti G, Isgro G. Body size, gender, and transfusions as determinants of outcome after coronary operations. Ann Thorac Surg 2008; 85:481-6.

39. Kaibori M, Saito T, Matsui K, Yamaoka M, Kamiyama Y. Impact of fresh frozen plasma on hepatectomy for hepatocellular carcinoma. Anticancer Res 2008;28:1749-55.

40. Sjoblom L, Hardemark HG, Lindgren A, Norrving B, Fahlén M, Samuelsson M, Stigendal L, Stockelberg D, Taghavi A, Wallrup L, Wallvik J. Management and prognostic features of intracerebral hemorrhage during anticoagulant therapy: a Swedish multicenter study. Stroke 2001;32:2567-74.

41. Yiu KH, Siu CW, Jim MH, Tse HF, Fan K, Chau MC, Chow WH. Comparison of the efficacy and safety profiles of intravenous vitamin $\mathrm{K}$ and fresh frozen plasma as treatment of warfarin-related over-anticoagulation in patients with mechanical heart valves. Am J Cardiol 2006; 97:409-11.

42. Dara SI, Rana R, Afessa B, Moore SB, Gajic O. Fresh frozen plasma transfusion in critically ill medical patients with coagulopathy. Crit Care Med 2005;33:2667-71.

43. Hirsh J, Guyatt G, Albers GW, Harrington R, Schunemann HJ. Executive summary: American College of Chest Physicians Evidence-Based Clinical Practice Guidelines (8th edition). Chest 2008;133 Suppl:71S-109S.

44. Gazzard BG, Henderson JM, Williams R. Early changes in coagulation following a paracetamol overdose and a controlled trial of fresh frozen plasma therapy. Gut 1975;16: 617-20.

45. Leese T, Holliday M, Heath D, Hall AW, Bell PR. Multicentre clinical trial of low volume fresh frozen plasma therapy in acute pancreatitis. Br J Surg 1987;74:907-11.

46. Leese T, Holliday M, Watkins M, Thomas WM, Neoptolemos JP, Hall C, Attard A. A multicentre controlled clinical trial of high-volume fresh frozen plasma therapy in prognostically severe acute pancreatitis. Ann R Coll Surg Engl 1991;73:207-14.

47. Etemadrezaie H, Baharvahdat H, Shariati Z, Lari SM, Shakeri MT, Ganjeifar B. The effect of fresh frozen plasma in severe closed head injury. Clin Neurol Neurosurg 2007; 109:166-71.

48. Khan H, Belsher J, Yilmaz M, Afessa B, Winters JL, Moore SB, Hubmayr RD, Gajic O. Fresh-frozen plasma and platelet transfusions are associated with development of acute lung injury in critically ill medical patients. Chest 2007;131: 1308-14.

49. Guven M, Sungur M, Eser B, Sari I, Altuntas F. The effects of fresh frozen plasma on cholinesterase levels and outcomes in patients with organophosphate poisoning. J Toxicol Clin Toxicol 2004;42:617-23. 